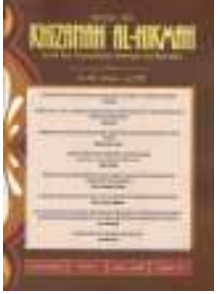

\title{
PERILAKU PENCARIAN INFORMASI MAHASISWA PASCASARJANA UIN ALAUDDIN MAKASSAR
}

\author{
Irvan Muliyadi*
}

Pengutipan: Muliyadi, I. (2018). Perilaku pencarian informasi mahasiswa pascasarjana UIN Alauddin Makassar. Khizanah al-Hikmah : Jurnal Ilmu Perpustakaan, Informasi, dan Kearsipan, 6(1), 01-11.

DOI: $10.24252 /$ kah.v6i1a1

\section{*Universitas Islam Negeri Alauddin Makassar \\ irvanmuliyadi71@gmail.com}

\section{ABSTRAK}

Penelitian ini mengenai perilaku pencarian informasi mahasiswa pascasarjana UIN Alauddin Makassa melalui survey dari 40 respondent yang berfokus pada; motivasi pencarian informasi, karakteristik kebutuhan informasi, perilaku pencarian informasi dan hambatan dalam pemerolehan informasi. Hasil penelitian menunjukkan bahwa aktivitas belajar mengajar seperti penulisan makalah dan pengembangan diri (profesionalitas) merupakan motivasi utama dalam melakukan pencarian informasi. Koleksi tercetak, koleksi digital, terbitan mutakhir dan terbitan klasik merupakan ciri utama bahan pustaka yang dibutuhkan mahasiswa pascasarjana meskipun dengan prensetasi yang berbeda. Perpustakaan, toko buku dan individu merupakan tempat yang lazim digunakan untuk mengecek keberadaan suatu terbitan, dan bab pengantar/pendahuluan, daftar isi dan judul merupakan bagian dari suatu terbitan yang sangat membantu mereka untuk penentuan tingkat relevansi dari suatu terbitan. Mahasiswa pascasarjana UIN Alauddin mengalami hambatan baik yang bersifat external maupun internal dalam pemerolehan bahan pustaka untuk memenuhi kebutuhan informasinya.

Kata kunci: Perilaku pencarian informasi; kebutuhan informasi

\section{ABSTRACT}

This research is about the information seeking behavior of postgraduate students at UIN Alauddin Makassar through a survey of 40 respondents with particular issues on; motivation of information seeking, characteristics of publication'needs, strategies of information searching, and barriers of information gathering. Class assignment and self actualitation are the main motivations of postgraduate students to seek information. Printed material, digital material, new publication and classical publication are the characteristics of information resources needed by the postgraduate students. Library, book store and people are the place for them to consult the availability of publications. Introduction, list of content, and title are the parts of publication which are commonly used as a strategy to judge the relevancy of an information resource. External and internal barriers are experienced by postgraduate students of UIN Alauddin in gathering information.

Keywords: Information seeking behavior; information need

\section{PENDAHULUAN}

Mengenali pemustaka yang mencakup perilaku informasi mereka adalah suatu tuntutan bagi perpustakaan (Katz, 1997).
Tuntutan ini diharapkan bisa memberikan arah bagi pengembangan perpustakaan khususnya sumber-sumber informasi yang akan dijadikan koleksi perpustakaan agar benar-benar mampu mendatangkan 
manfaat yang besar bagi pemustaka. Pemilihan sumber informasi yang tepat bagi pemakai (Spiller, 1996) sebagai salah satu prinsip dalam menyeleksi bahan pustaka hanya bisa dicapai melalui pemahaman yang mendalam terhadap pemustaka. Oleh karena itu survey atau penelitian mengenai pemustaka sebaiknya dilakukan secara berkala untuk meningkatkan layanan perpustakaan (Bonk, 1990).

Arah kajian perilaku informasi telah mengalami perubahan dari yang tadinya berpusat pada bagaimana suatu sistem informasi dimanfaatkan oleh pemustaka ke bagaiamana kondisi, peran atau pekerjaan dan lingkungan seseorang berpengaruh terhadap terhadap perilaku informasi mereka (Wilson, T. D. 2000). Disiplin ilmu, tanggungjawab atau pekerjaan, waktu yang tersedia, spesifikasi keilmuan dan organisasi adalah sangat menentukan perilaku informasi seseorang (Palmer, 1991).

Meskipun terjadi perubahan arah penelitian mengenai perilaku informasi, namun penelitian mengenai pemakai yang menitikberatkan pada pemanfaatan lembaga informasi pun masih banyak dilakukan, misalnya, penelitian tentang penggunaan sarana temu kembali informasi, penelitian tentang pemanfaatan layanan perpustakaan dan pemanfaatan koleksi perpustakaan (Krikelas, 1993). Hal ini disebabkan adanya kebutuhan untuk mengevaluasi pengelolaan perpustakaan yang selanjutnya akan bermanfaat untuk meningkatkan layanannya.

Fungsi dan tugas utama perpustakaan perguruan tinggi adalah memenuhi kebutuhan informasi civitas akademika khususnya kebutuhan informasi yang berkaitan pelaksanaan Tridarma Perguruan Tinggi, yang mencakup kegiatan pendidikan / pengajaran, penelitian serta pengabdian masyarakat. Mahasiswa sebagai civitas akademika membutuhkan literatur seperti buku atau jurnal yang relevan untuk menyelesaikan tugas dari dosennya. Perpustakaan diharapkan mampu memenuhi kebutuhan informasi tersebut yang pada akhirnya perpustakaan turut memberikan kontribusi yang signifikan terhadap peningkatan mutu pendidikan.

Pengetahuan yang mendalam mengenai perilaku pencarian informasi mahasiswa pascasarjana sangat dibutuhkan untuk meningkatkan layanan perpustakaan UIN Alauddin. Oleh karena itu, penelitian ini perlu dilaksanakan. Penelitian ini difokuskan pada; motivasi mahasiswa pascasarjana dalam melakukan pencarian informasi, karakteristik sumber informasi yang mereka butuhkan, perilaku pencarian informasinya, serta hambatan yang dialami untuk memperoleh informasi.

\section{TINJAUAN LITERATUR}

Perilaku informasi merupakan salah satu area penelitian dalam Ilmu Perpustakaan dan Informasi yang menitikberatkan pada perilaku informasi manusia yang berkaitan dengan strategi pencarian dan penemuan informasi, penataan informasi dan pemanfaatan informasi (Spink \& Cole 2006).

Beragam model dalam literatur yang menjelaskan konsep perilaku informasi. Sejumlah model yang menjelaskan konsep tersebut dalam konteks yang lebih luas misalnya model perilaku informasi yang diperkenalkan oleh Wilson 1981 dan Dervin 1983. Menurut Wilson model 1981, kondisi perorangan (fisiologi, kognitif dan afektif), peran dan tuntutan pekerjaan serta lingkungan (politik, 
ekonomi, teknologi) berkaitan dengan perilaku informasi seseorang (Wilson, 2000). Demikian juga dalam Dervin Model 1983, perilaku informasi manusia tidak bisa dilepaskan dengan empat elemenelemen utama yakni; konteks baik yang berkaitan dengan waktu maupun yang berhubungan dengan tempat, gap atau ketidaktahuan seseorang, perilaku mereka untuk mengatasi gap tersebut baik yang berkaitan dengan pencarian maupun yang berhubungan dengan usaha-usaha dalam memahami informasi yang telah ditemukan.

Beberapa model perilaku informasi yang lain memiliki fokus pada aktifitas yang terjadi pada saat melakukan pencarian informasi. Misalnya model perilaku informasi yang diperkenalkan oleh Ellis yang menjelaskan karakteristik perilaku informasi peneliti yang mencakup Starting, Chaining, Browsing, Differentiating, Monitoring, Extracting, dan Verifying. Starting adalah strategi yang digunakan oleh seseorang dalam memulai suatu pencarian informasi misalnya bertanya kepada temannya yang dianggap memilki pengetahuan yang cukup mengenai terbitan yang mereka butuhkan. Chaining adalah kegiatan melihat-lihat catatan kaki, sitasi atau daftar pustaka dari suatu terbitan untuk menentukan judul-judul terbitan yang relevan dengan kebutuhannya. Browsing adalah kegiatan penelusuran atau pencarian terhadap judul-judul terbitan yang dianggap relevan dengan kebutuhannya pada suatu sistem informasi. Differentiating adalah kegiatan memilah-milah terbitan yang dianggap relevan dan tidak relevan dengan kebutuhannya dengan menggunakan kriteria-kriteria tertentu. Monitoring adalah kegiatan seseorang untuk tetap mengikuti terbitan atau informasi terbaru dalam bidang yang mereka teliti.
Extracting adalah kegiatan mengidentifikasi informasi yang relevan dari suatu terbitan. Verifying adalah kegiatan mengecek tingkat akurasi suatu informasi.

Model perilaku informasi yang lain adalah Khulthau Model. Model ini menjelaskan perilaku informasi yang dibagi ke dalam berbagai tahapan. Setiap tahapan memiliki ciri aktifitas dan perasaan tertentu yang dialami oleh pencari informasi. Tahapan tersebut adalah inisiasi, seleksi, eksplorasi, formulasi dan presentasi. Kedua model perilaku informasi yang diperkenalkan oleh Ellis dan Khulthau merupakan model informasi yang bersifat linier. Model perilaku informasi lainnya adalah Allan Foster model. Allan membagi karakteristik perilaku informasi ke dalam tiga tahap utama yaitu opening, orientation dan consultation. Menurut Allan ketiga tahapan tersebut bersifat iteratative dan non-linier (Foster, 2004).

$\begin{aligned} & \text { Meskipun konsep kebutuhan } \\ & \text { sebagai }\end{aligned}$
informasi diartikan seseorang
ketidakcukupan pengetahuan sesang
untuk memecahkan masalah yang sedang
mereka hadapi (Miranda \& Tarapanoff,
2008), namun istilah kebutuhan informasi
itu sendiri bersifat polemik karena seperti
apa informasi yang dibutuhkan seseorang
adalah sesuatu yang tidak terlalu jelas
(Cole, 2001; Belkin, 1982; Wersig \&
Windel, 1985). Istilah kebutuhan informasi
juga sering membingunkan karena
kadang-kadang istilah tersebut dianggap
sebagai kebutuhan primer padahal
kebutuhan informasi adalah suatu
kebutuhan manusia dalam rangka
pemenuhan kebutuhan primer (Wilson,
2000).

Ketidakcukupan informasi atau pengetahuan yang sering diistilahkan 
dengan kebutuhan informasi dapat dibagi ke dalam dua kategori yaitu, recognized need atau anticipated need dan unrecognized need atau unexpected need (Savolainen, 2006). Recognized need adalah gap yang dikenali sebelum seseorang melakukan pencarian informasi sementara unexpected need adalah gap yang dikenali pada saat seseorang melakukan kegiatan pencarian informasi atau pada saat seseorang berinteraksi dengan informasi. Kebutuhan informasi juga dapat dikategorikan berdasarkan tingkat prioritas yakni immediate need dan deferred need. Immideate need adalah kebutuhan informasi yang sifatnya mendesak dan diperlukan sekarang sementara deferred need adalah kebutuhan informasi yang belum perlukan sekarang sehingga seseorang memiliki kecenderungan untuk menyimpan informasi tersebut (Wilson, 2000).

Perilaku pencarian informasi adalah aktivitas pencarian informasi yang dilakukan oleh seseorang untuk memenuhi suatu kebutuhan tertentu (Spink \& Cole, 2006; Wilson, 2000). Aktivitas pencarian informasi merupakan salah satu bagian dari perilaku informasi (Spink \& Cole, 2006) yang selalu berhubungan dengan konteks (Blandford \& Attfield, 2010). Keinginan seseorang untuk mencapai tujuan-tujuan tertentu menjadi navigasi terhadap perilaku pencarian informasi itu sendiri (Hughes, Wareham \& Joshi, 2010). Oleh karena kebutuhan informasi seseorang terus berevolusi atau berubah-ubah maka tahapan-tahapan yang terdapat dalam kegiatan pencarian dan penelusuran informasi bersifat iteratative (Blandford \& Attfield, 2010)

Perilaku penelusuran informasi adalah perilaku pada level mikro dari seseorang pada saat mereka berinteraksi dengan suatu sistem informasi (Wilson, 2000). Perilaku penelusuran tersebut mencakup kegiatan fisik seperti kegiatan menklik tautan, kegiatan intelektual dan mental seperti penggunaan boolean operator atau penggunaan kriteria-kriteria tertentu untuk menentukan tingkat relevansi dari informasi yang mereka temukan (Wilson, T.D. 2000).

Kegiatan fisik, intelektual dan mental pada saat seseorang melakukan pencarian informasi sangat dipengaruhi oleh berbagai faktor misalnya pengalaman seseorang, kondisi atau keadaan fisik, sikap dan mental seseorang, gaya belajar seseorang, faktor demografi, dan subjek atau topik dari informasi yang mereka butuhkan (Hughes, Wareham \& Joshi 2010).

Selama pencarian informasi, seseorang boleh jadi mengalami hambatanhambatan. Hambatan dalam pencarian informasi adalah kendala atau sesuatu yang dapat menghalangi seseorang dalam mendapatkan informasi tersebut (Savolainen, 2006). Kendala atau hambatan dapat dikelompokkan ke dalam dua jenis yaitu internal barrier dan external barrier. Internal barrier adalah kendala yang berasal dari dalam diri individu itu sendiri sedangkan external barrier adalah kendala yang berasal dari luar diri individu itu sendiri. Internal barrier meliputi sikap dan pengetahuan seseorang misalnya seseorang yang enggan untuk mengakses suatu informasi dikarenakan rasa was-was atau rasa takut setelah mengakses informasi tersebut. Sedangkan dari segi pengetahuan yang bisa menjadi penghalang bagi seseorang untuk mengakses informasi adalah ketidaktahuan seseorang untuk menentukan informasi mana yang relevan dan tidak relevan bagi mereka atau 
keterbatasan skill yang berkaitan dengan strategi penelusuran. External barrier adalah hambatan yang berkaitan dengan aspek tempat, waktu dan budaya masyarakat di mana seseorang itu tinggal (Savolainen, 2006).

\section{METODOLOGI PENELITIAN}

Penelitian ini merupakan penelitian deskriptif yang dilakukan terhadap mahasiswa pascasarjana UIN Alauddin untuk mengetahui perilaku pencarian informasi 40 mahasiswa pascasarjana UIN Alauddin yang berpartisipasi dalam penelitian ini. Mereka adalah mahasiswa program magister dan doktor yang sementara menulis tesis/disertasi. Mereka dipilih karena memiliki banyak pengalaman dalam pencarian informasi baik dalam penulisan makalah maupun dalam penulisan tugas akhir mereka yang sementara berlangsung.

Angket adalah instrumen yang dipakai untuk mengumpulkan data primer yang berhubungan dengan variabel yang ada dalam penelitian ini yakni motivasi mahasiswa pascasarjana UIN Alauddin dalam pencarian informasi, sumber pemerolehan informasi dalam menyelesaikan tugas-tugasnya, perilaku pencarian informasi dan hambatan dalam pencarian informasi. Model angket yang dipakai adalah angket tertutup dengan menggunakan skala likert. Respondent diharapkan memilih salah satu opsi yang relevan dengan dirinya dari sekian banyak opsi yang disediakan oleh peneliti. Peneliti melakukan tabulasi dari setiap item pertanyaan yang diajukan untuk melihat persentasi variabel-variabel yang diteliti.

\section{HASIL PENELITIAN DAN PEMBAHASAN}

\section{a. Motivasi Mahasiswa Pascasarjana UIN Alauddin Makassar dalam Melakukkan Pencarian Informasi}

Responden diminta untuk memberikan ceklist berdasarkan skala likert dari 5 ragam motivasi dalam melakukan pencarian informasi. Tabel 1 menunjukkan persentasi dari lima ragam motivasi dalam melakukan pencarian informasi. Meskipun perbedaan persentasi dari ke lima ragam motivasi pencarian informasi tidak terlalu signifikan, rasa ingin tahu atau memahami $(60 \%)$ dan penulisan makalah $(60 \%)$ merupakan motivasi yang menempati rating pertama dari ke lima ragam motivasi pencarian informasi. Penyediaan sumber informasi khususnya yang berkaitan dengan motivasi mahasiswa pascasarjana melakukan pencarian informasi karena alasan penulisan makalah (60\%) dan keinginan berpartisipasi dalam diskusi kelas (55\%) akan lebih mudah dikenali oleh pihak perpustakaan. Oleh karena, judul makalah atau topik pembahasan dari setiap mata kuliah di pascasarjana sudah ditetapkan oleh setiap dosen pengampu mata kuliah.

Sebaliknya, pemenuhan literatur khususnya yang berkaitan dengan motivasi; rasa ingin tahu atau memahami (60\%), kebutuhan aktualisasi diri (55\%), dan penulisan tugas akhir baik tesis atau disertasi (52\%) dalam melakukan pencarian informasi akan lebih kompleks dikenali oleh pihak perpustakaan oleh karena setiap individu memiliki rasa ingin tahu, kebutuhan aktualisasi diri dan judul tesis dan disertasi yang berbeda-beda. 
Tabel 1. Motivasi mahasiswa pascasarjana UIN Alauddin melakukan pencarian informasi

\begin{tabular}{c|l|c}
\hline No & \multicolumn{1}{|c|}{ Ragam motivasi } & $\%$ \\
\hline 1 & Hasrat ingin tahu dan memahami & $(60 \%)$ \\
\hline 2 & Penulisan makalah & $(60 \%)$ \\
\hline 3 & Kebutuhan aktualisasi diri & $(55 \%)$ \\
\hline 4 & $\begin{array}{l}\text { Penulisan tugas akhir } \\
\text { (tesis/disertasi) }\end{array}$ & $(52 \%)$ \\
\hline 5 & $\begin{array}{l}\text { Kebutuhan berpartisipasi dalam } \\
\text { diskusi kelas }\end{array}$ & $(50 \%)$ \\
\hline
\end{tabular}

Sumber: survey September 2015

\section{b. Karakteristik Kebutuhan Informasi Mahasiswa Pascasarjana UIN Alauddin Makassar}

Responden yang sama juga diberikan pilihan untuk memberikan jawaban terhadap ragam dan karakteristik sumber informasi yang mereka butuhkan untuk mendapatkan gambaran kebutuhan informasi mahasiswa pascasarjana UIN Alauddin. Tabel 2 adalah persentase dari lima ragam sumber informasi yang lazim digunakan oleh mahasiswa pascasarjana, sementara tabel 3 adalah persentase karakteristik sumber informasi yang dibutuhkan oleh mahasiswa dilihat dari segi tahun publikasinya.

\section{Hampir semua mahasiswa} pascasarjana UIN Alauddin menyatakan bahwa buku tercetak (87,5\%) adalah bentuk sumber informasi yang mereka butuhkan. Sementara sumber informasi elektronik baik buku elektronik (65\%) maupun jurnal elektronik (65\%) merupakan bentuk sumber informasi yang cukup banyak dibutuhkan oleh mahasiswa pascasarjana UIN Alauddin. Hal ini merupakan suatu indikasi bahwa penyediaan literatur mahasiswa pascasarjana harus lebih banyak persentasinya kepada buku tercetak dibandingkan sumber elektronik. Namun, hal ini tidak berarti bahwa jumlah anggaran yang dialokasikan untuk penyediaan buku tercetak harus lebih besar dibandingkan penyediaan sumber elektronik karena umumnya melanggan sumber informasi elektronik jauh lebih besar biayanya dibandingkan penyediaan sumber buku tercetak. Kebijakan untuk melanggan surat kabar tercetak dan jurnal tercetak juga tetap dipertahankan karena jumlah responden yang masih menggunakan sumber informasi tersebut untuk memenuhi kebutuhan informasi mereka masih signifikan (55\% dan 57\%).

Tabel 2. Sumber pemerolehan informasi (jenis literatur) yang digunakan mahasiswa pascasarjana UIN Alauddin

\begin{tabular}{c|l|c}
\hline No & \multicolumn{1}{|c|}{ Jawaban } & $\%$ \\
\hline 1 & Buku tercetak & $(87,5 \%)$ \\
\hline 2 & Buku elektronik & $(65 \%)$ \\
\hline 3 & Elektronik jurnal & $(65 \%)$ \\
\hline 4 & Artikel jurnal tercetak & $(57,5 \%)$ \\
\hline 5 & Artikel surat kabar & $(55 \%)$ \\
\hline
\end{tabular}

Sumber: survey September 2015

Dilihat dari segi tahun publikasi dari literatur yang dibutuhkan oleh mahasiswa pascasarjana UIN Alauddin, terbitan mutakhir masih mendominasi sebagai terbitan yang paling banyak digunakan oleh mahasiswa pascasarjana UIN Alauddin yakni masing masing dengan persentasi; terbitan tahun 2000-an (67\%), terbitan tahun 2010-an (62\%) dan terbitan tahun 1990-an (60\%). Ini merupakan indikasi perlunya prioritas kemuthakhiran dalam penyediaan literatur bagi mahasiswa pascasarjana UIN Alauddin. Hasil survey juga menunjukkan bahwa literatur klasik pun masih diperlukan oleh mahasiswa pascasarjana UIN Alauddin meskipun dengan persentasi di bawah rata-rata, misalnya literature terbitan tahun 1980-an, 1970-an dan 1960-an dengan presentasi $(45 \%, 30 \%$ dan 20\%). 
Hal ini menunjukkan perlunya untuk mempertahankan literatur klasik di perpustakaan untuk pemenuhan kebutuhan informasi mahasiswa pascasarjana UIN Alauddin. Usaha untuk mempertahankan literature klasik dapat dilakukan melalui kegiatan pelestarian dan perawatan bahan-bahan pustaka.

Tabel 3. Tahun publikasi dari literatur yang digunakan mahasiswa pascasarjana

UIN Alauddin

\begin{tabular}{c|l|c}
\hline No & \multicolumn{1}{|c|}{ Jawaban } & $\%$ \\
\hline 1 & Publikasi tahun 2000-an & $(67 \%)$ \\
\hline 2 & Publikasi tahun 2010-an & $(62 \%)$ \\
\hline 3 & Publikasi tahun 1990-an & $(60 \%)$ \\
\hline 4 & Publikasi tahun 1980-an & $(45 \%)$ \\
\hline 5 & Publikasi tahun 1970-an & $(30 \%)$ \\
\hline 6 & Publikasi tahun 1960-an & $(20 \%)$ \\
\hline
\end{tabular}

Sumber: survey September 2015

c. Perilaku Pencarian Informasi Mahasiswa Pascasarjana UIN Alauddin Makassar

Responden memberikan menggunakan skala likert terhadap lima strategi yang umum digunakan oleh pemustaka dalam mengecek bahan pustaka yang sesuai dengan informasi yang mereka butuhkan (lihat tabel 4). Berkunjung ke toko buku (80\%) merupakan strategi yang lebih lazim digunakan oleh mahasiswa pascasarjana UIN Alauddin dibandingkan dengan mengecek katalog perpustakaan (77\%). Ini adalah suatu indikasi bahwa toko buku memberikan suatu kenyamanan atau daya tarik tertentu bagi mahasiswa dibandingkan dengan perpustakaan.
Bertanya atau meminta bantuan kepada teman $(70 \%)$ juga lebih lazim digunakan dibandingkan dengan meminta bantuan petugas perpustakaan (50\%) oleh mahasiswa pascasarjana UIN Alauddin untuk mengecek keberadaan bahan pustaka yang sesuai kebutuhannya.

Meskipun perbedaan persentasi ini tidak terlalu signifikan, namun perlu dicatat bahwa teman merupakan tempat yang nyaman untuk menanyakan keberadaan suatu bahan pustaka dibandingkan petugas perpustakaan. Memeriksa daftar pustaka (75\%) atau bibliografi juga merupakan strategi yang umum digunakan oleh mahasiswa pascasarjana UIN untuk mengecek bahan pustaka yang relevan dengan kebutuhannya. Hal ini merupakan suatu masukan bagi pengkatalog untuk menampilkan daftar bibliografi dari setiap item bahan pustaka yang mereka katalog dalam rangka memaksimalkan pelayanan mereka terhadap pemustaka yang melakukan pencarian literatur.

Pengkatalog juga sudah saatnya mempertimbangkan untuk memungkinkan pemustaka mengakses pengantar atau pendahuluan (75\%) suatu item bahan pustaka dan daftar isi suatu bahan pustaka $(67,5 \%)$ pada saat mereka menggunakan OPAC. Tabel 5 menunjukkan bahwa pengantar dan daftar isi suatu bahan pustaka merupakan strategi yang lazim digunakan oleh mahasiswa pascasarjana untuk menetukan relevansi bahan pustaka dengan kebutuhannya.

Tabel 4. Strategi untuk mengecek keberadaan terbitan yang mereka butuhkan

\begin{tabular}{l|l|l}
\hline No & Strategi mengecek terbitan & $\%$ \\
\hline
\end{tabular}




\begin{tabular}{c|l|c}
\hline 1 & Berkunjung ke toko buku, & $(80 \%)$ \\
\hline 2 & Menggunakan katalog perpustakaan & $(77 \%)$ \\
\hline 3 & Memeriksa daftar pustaka & $(75 \%)$ \\
\hline 4 & Bertanya kepada teman & $(70 \%)$ \\
\hline 5 & $\begin{array}{l}\text { Meminta bantuan petugas } \\
\text { perpustakaan }\end{array}$ & $(50 \%)$ \\
\hline
\end{tabular}

Sumber: survey September 2015

Tabel 5. Strategi mengecek relevansi bahan pustaka dengan topik mereka

\begin{tabular}{|c|c|c|}
\hline No & Strategi mengecek relevansi & $\%$ \\
\hline 1 & $\begin{array}{l}\text { Membaca bab pengantar atau } \\
\text { pendahuluan }\end{array}$ & (75\%) \\
\hline 2 & Melihat daftar isi suatu terbitan & $(67,5 \%)$ \\
\hline 3 & Melihat judul buku & $(62,5 \%)$ \\
\hline
\end{tabular}

Sumber: survey September 2015

\section{d. Hambatan dalam Pemerolehan Informasi yang Dialami oleh Mahasiswa Pascasarjana UIN Alauddin}

Responden diminta

untuk memberikan jawaban berdasarkan skala likert dari enam item hambatan yang mereka alami dalam pemerolehan informasi yang mereka butuhkan (lihat tabel 6). Literatur yang mereka butuhkan tidak tersedia di perpustakaan $(77,5)$ merupakan hambatan paling banyak dihadapi oleh mahasiswa pascasarjana UIN Alauddin. Tidak tersedianya literature yang mereka butuhkan menunjukkan bahwa layanan perpustakaan kepada mahasiswa pascasarjana belum mencapai level yang memuaskan. Ketidaktersedianya literatur yang mereka butuhkan di perpustakaan juga merupakan indikasi keterbatasan anggaran pengadaan buku perpustakaan atau keterbatasan komunikasi antara pihak perpustakaan dan pascasarjana khususnya yang berhubungan pengadaan buku buku perpustakaan.
Katalog perpustakaan kurang mendukung untuk melakukan pencarian buku yang dibutuhkan (72,5\%) merupakan hambatan yang banyak dialami oleh mahasiswa pascasarjana UIN Alauddin dalam melakukan pencarian informasi. Hambatan ini bisa disebabkan oleh ketidaktahuan pemustaka menggunakan OPAC (Online Public Access Catalog) yang telah disediakan oleh perpustakaan atau keterbatasan fitur-fitur pencarian atau informasi bibliografis yang disediakan oleh OPAC perpustakaan. Susunan buku di rak kurang mendukung untuk menemukan terbitan yang mereka cari (70\%) juga menjadi kendala umum oleh mahasiswa pascasarjana. Hal ini menunjukkan keterbatasan perpustakaan khususnya yang berkaitan penyusunan kembali buku-buku di rak.

Pada kebanyakan perpustakaan, penyusunan buku-buku di rak dilakukan oleh staf yang memiliki skill mengabjad dan nomor klasifikasi yang biasanya diperoleh melalui training atau pengalaman bekerja di perpustakaan. Petugas perpustakaan kurang membantu untuk menemukan literatur yang mereka butuhkan $(47,5 \%)$ juga merupakan hambatan yang cukup banyak dialami oleh mahasiswa pascasarjana UIN Alauddin. Hal ini menunjukkan keterbatasan staf dalam memberikan pelayanan prima kepada pemustaka. Keterbatasan ini kemungkinannya disebabkan oleh bahwa mereka belum memiliki skill dalam memberikan layanan prima yang biasanya diperoleh melalui pelatihan pelayanan prima yang diselenggarakan oleh instansi-instansi terkait misalnya Perpustakaan Nasional RI. Daya beli mahasiswa (65\%) terhadap literatur yang mereka butuhkan juga merupakan hambatan yang lazim bagi mereka untuk memenuhi kebutuhan informasi mereka. Umumnya, 
perpustakaan menyiapkan kotak saran untuk menghimpun daftar buku-buku yang menjadi kebutuhan mahasiswa. Strategi ini memungkinkan perpustakaan untuk mengatasi hambatan external pemustaka dalam memenuhi kebutuhan informasi mereka. Tidak tersedianya buku yang mereka butuhkan di toko buku $(62,5 \%)$ merupakan kendala lain yang umum dialami oleh mahasiswa pascasarjana UIN Alauddin. Pinjam antar perpustakaan umumnya dapat mengatasi hambatan tersebut dan hambatan tidak tersedianya buku di perpustakaan.

Tabel 6. Hambatan dalam pemerolehan literatur untuk pemenuhan kebutuhan informasi

\begin{tabular}{c|l|c}
\hline No & $\begin{array}{l}\text { Hambatan dalam pemerolehan } \\
\text { literature }\end{array}$ & $\%$ \\
\hline 1 & $\begin{array}{l}\text { Literatur yang mereka butuhkan } \\
\text { tidak tersedia di perpustakaan } \\
\text { pusat, }\end{array}$ & $(77,5 \%)$ \\
\hline 2 & $\begin{array}{l}\text { Katalog perpustakaan kurang } \\
\text { mendukung untuk melakukan } \\
\text { pencarian buku yang dibutuhkan }\end{array}$ & $(72,5 \%)$ \\
\hline 3 & $\begin{array}{l}\text { Susunan buku di rak tidak terlalu } \\
\text { mendukung untuk menemukan } \\
\text { buku yang mereka butuhkan }\end{array}$ & $(70 \%)$ \\
\hline 5 & $\begin{array}{l}\text { Literatur yang mereka butuhkan } \\
\text { harganya sangat mahal }\end{array}$ & $\begin{array}{l}\text { Literatur yang mereka butuhkan } \\
\text { tidak tersedia di toko buku }\end{array}$ \\
\hline 6 & $\begin{array}{l}\text { Petugas perpustakaan kurang } \\
\text { membantu untuk menemukan } \\
\text { literatur yang mereka butuhkan }\end{array}$ & (62,5\%) \\
\hline
\end{tabular}

Sumber: survey September 2015

\section{KESIMPULAN DAN IMPLIKASI PENELITIAN}

a. Kesimpulan

1) Mahasiswa pascasarjana UIN Alauddin selain memiliki kesamaan motivasi dalam melakukan pencarian informasi, mereka juga memiliki perbedaan motivasi dalam melakukan pencarian informasi. Kesamaan motivasi tersebut dimungkinkan karena mereka mengambil mata kuliah yang sama misalnya dalam penulisan makalah yang akan dipresentasikan di kelas dan perbedaan motivasi dimungkinkan karena perbedaan minat dan topik penelitian mereka.

2) Mahasiswa Pascasarjana UIN Alauddin memanfaatkan lebih banyak sumber informasi tercetak dan terbitan mutakhir dibandingkan sumber informasi elektronik dan terbitan klasik. Namun perlu dicatat sumber informasi digital seperti e-book dan e-journal sudah semakin sering digunakan oleh mahasiswa pascasarjana UIN Alauddin. Demikian juga, terbitan-terbitan klasik masih tetap digunakan oleh mereka meskipun dengan persentasi yang rendah.

3) Perpustakaan, toko buku, individu misalnya teman dan pegawai perpustakaan, dan daftar pustaka merupakan tempat yang lebih sering digunakan mahasiswa pascasarjana untuk mencari tahu terbitan-terbitan yang mereka butuhkan. Untuk menentukan apakah suatu terbitan relevan atau tidak dengan kebutuhannya, mereka umumnya melihat pengantar atau pendahuluan, daftar isi dan judul terbitan itu sendiri.

4) External barrier seperti ketidaktersedianya terbitan yang dibutuhkan di perpustakaan, susunan buku di rak, fitur katalog dan sikap staf perpustakaan merupakan hambatan yang lebih sering dialami oleh mahasiswa pascasarjana dibandingkan dengan internal barrier misalnya daya beli mahasiswa. 


\section{b. Implikasi penelitian}

1) Perpustakaan UIN Alauddin sebaiknya secara berkala melakukan kajian kebutuhan pemustakanya kepada mahasiswa pascasarjana untuk mengetahui topik terhadap tugas mahasiswa dari berbagai mata kuliah dan area atau minat kajian mahasiswa pascasarjana. Hal ini sangat diperlukan agar referensi yang diadakan oleh perpustakaan benarbenar adalah referensi yang dibutuhkan oleh mereka.

2) Perpustakaan UIN Alauddin sebaiknya menyediakan akses mahasiswa pascasarjana terhadap ebook dan e-jurnal. Selain itu, juga menyediakan terbitan-terbitan mutakhir sekaligus tetap mempertahankan terbitan klasik yang masih banyak dimanfaatkan oleh mahasiswa pascasarjana.

3) Perpustakaan UIN Alauddin mengupayakan kerjasama dengan penerbit misalnya melalui dengan book-fair agar mahasiswa pascasarjana mendapatkan harga yang lebih murah saat membeli buku.

4) Perpustakaan UIN Alauddin hendaknya terus berusaha untuk melakukan perbaikan terhadap katalog perpustakaan termasuk informasi yang harus ditampilkan dalam katalog sudah harus memuat pengantar/pendahuluan dan daftar isi dari suatu terbitan dan bibliografi suatu terbitan untuk lebih memudahkan mereka mengecek terbitan-terbitan yang sesuai dengan kebutuhan informasinya. Demikian juga susunan buku di rak benar-benar harus disusun dengan sistematis sehingga dapat membantu pemustaka menemukan terbitan dengan cepat.

\section{DAFTAR PUSTAKA}

Auster, E. (1992). ‘Organizational behavior and information seeking: lessons for librarians', Spesial library association, July: 173-181.

Bawden, D. (1990). 'User oriented evaluation of information system and services', London: Gower.

Blandford, A., and Attfield, S. (2010). 'Interacting with information', London : Morgan \&Claypool.

Bloomberg, M., and Evans, G. E. (1995). 'Introduction to technical services for library technicians'. $5^{\text {th }}$ ed. Littletown, Col. : Library Unlimited, 1995.

Bonk, W. J. (1990). 'Building library collections'. 5th Ed. London: The Scarecrow Press.

Buck, R. (1998). 'Human motivation and emotion', New York: John Wiley.

Buckland, M. K. (1998). 'Library services in theory and context'. $2^{\text {nd }}$. Ed. Oxford : Pergamon Press.

Cofer, C. N., and Appley, M. H. (1964). 'Motivation: theory and research', New York: John Wiley \&Sons.

Devadson, F. J., and Pratap, P. L. (1996). 'Steps for identifying information needs of Clients', in Proceeding the tenth Congress of Southeast Asian Librarians(CONSAL X), May 21-25, Kuala Lumpur Malaysia.

Katz, W. A. (1997), 'A collection Development: The selection of materials for libraries', Holt Rinerharst and Winston.

Krikelas, J. (1993), 'Information seeking behavior pattern and concept'. Drexel Library Quarterly. Vol. 19 (2) Spring. p. 123-146

Foster, A. (2004). 'A non-linear model of information-seeking behavior', Journal of the American society for information science and technology, vol. 55, no. 3, pp. 228-237. 
Hughes, B, Wareham, J., and Joshi, I. (2010). 'Doctors' online information needs, cognitive search strategies, and judgments of information quality and cognitive authority: How predictive judgments introduce bias into cognitive search models', Journal of the American Society for Information Science and Technology, vol. 61, no. 3, pp. 433452.

Wijayanti, L. (2001) 'Kebutuhan dan Perilaku Pencarian Informasi Staf Pengajar Fakultas Sastra Univeristas Indonesia dalam Rangka Mengerjakan Penelitian tahun 2000', Depok ; Program Studi Ilmu Perpustakaan, Informasi dan Kearsipan Bidang Ilmu Budaya Program Pascasarjana Universitas Indonesia.

Savolainen, R. (2007). 'Information source horizons and source preferences of environmental activists: A social phenomenological approach', Journal of the American Society for Information Science and Technology, vol. 58, no. 12, pp. 1709-1719

Savolainen, R. (2006). 'Approaches to socio-cultural barriers to information seeking', Library $\mathcal{E}$ Information Science Research, vol. 38, no. 1, pp. 52-59.

Savolainen, R. (2006). 'Information seeking and searching strategies as plans and patterns of action A conceptual analysis', Journal of Documentation, vol. 72, no. 6, pp. 1154-1180

Spink, A, and Cole, C. (2006). 'Human information behavior: Integrating diverse approaches and information use', Journal of the American Society for Information Science and Technology, vol. 57, no. 1, pp. 25-35
Spiller, D. (1990). Book Selection": An introduction to principles and practices. $4^{\text {th }}$ ed. London. Bingley.

Tenopir, C., Wang, P. Z., Y, Simmons, B., and Pollard, R. (2008). 'Academic users' interactions with Science Direct in search tasks: Affective and cognitive behaviors', Information Processing \& Management, vol. 44, no. 1, pp. 105-121

$\mathrm{Xu}, \mathrm{Y}$, Tan, BCY, and Yang, L (2006). 'Who will you ask? An empirical study of interpersonal task information seeking', Journal of the American Society for Information Science and Technology, vol. 57 , no. 12 , pp. $1666-$ 1677.

Wilson, TD. (2000). 'Human Information Behavior', Informing Science The International Journal of an Emerging Transdiscipline, vol. 3, no. 2, pp. 4956 